Goldschmidt 2021 Abstract

https://doi.org/10.7185/gold2021.7459

\section{Heterogeneous mineral nucleation controls the thermodynamic equilibria in multiphase inclusions}

\author{
NADIA MALASPINA ${ }^{1}$, MARCELLO CAMPIONE ${ }^{2}$, \\ MATTEO ALVARO ${ }^{3}$, MATTIA LA FORTEZZA ${ }^{4}$, SIMONE \\ TUMIATI $^{5}$ AND MARCO SCAMBELLURI $^{6}$ \\ ${ }^{1}$ Università Milano - Bicocca DISAT_CSS1 \\ ${ }^{2}$ University of Milano-Bicocca \\ ${ }^{3}$ University of Pavia \\ ${ }^{4}$ University of Genova \\ ${ }^{5}$ University of Milan \\ ${ }^{6}$ Distav \\ Presenting Author: nadia.malaspina@unimib.it
}

Multiphase inclusions are microenvironments where the interaction between the fluid and the host mineral might follow crystallisation pathways unpredictable by simple equilibrium thermodynamics.

The ultrahigh pressure (UHP) garnet-orthopyroxenites from the Maowu Ultramafic Complex (China) derive form metasomatic interaction of mantle rocks with siliceous fluids. In these rocks, garnet hosts solid multiphase primary inclusions consisting of spinel, amphibole, chlorite and talc, where spinel and chlorite are in epitaxial relationship with garnet [1]. Starting from this case study, [2] demonstrated that inclusions in mantle garnet filled with slab-derived fluids can re-equilibrate to a pyrope + spinel + chlorite assemblage at UHP conditions by a dissolution-precipitation mechanism, triggered by a dilute fluid. Similar inclusion/host relations are recorded by magnetitebearing multiphase inclusions hosted in metamorphic olivine of harzburgites from the Almirez Complex (Spain). In this latter occurrence inclusions are interpreted as remnants of an aqueous subduction-zone fluid produced by dehydration of former serpentinite [3]. Microfocus single-crystal X-ray diffraction demonstrated that the preferential crystallographic orientation relationships between the olivine host and the magnetite inclusion results from epitaxial growth of magnetite on olivine [4].

These relationships play a fundamental role in favouring the heterogeneous nucleation of spinel on garnet and of magnetite on olivine. Epitaxy requires that interface processes like heterogeneous nucleation play a role on the dynamics of phase nucleation and in attainment of thermodynamic equilibrium. This interaction might be so strong that mineral nucleation can occur even at undersaturation of the fluids. If applied to larger scales than the micrometric fluid inclusion-host system, the kinetic process described here suggests that fluid/mineral interfaces can play a key role in driving crystallization of neoblastic minerals.

References:

[1] Malaspina N., Alvaro M., Campione M., Wilhelm H., Nestola F. (2015) Contributions to Mineralogy and Petrology, 169 (3), $1-12$

[2] Campione M., Tumiati S., Malaspina N. (2017) Geochemical Perspective Letters, 4, 19-23

[3] Scambelluri M., Bottazzi P., Trommsdorff V., Vannucci
R., Hermann J., Gomez-Pugnaire M.T., Lopez-Sanchez Vizcaino V. (2001) Earth and Planet Science Letters 192, 457-470

[4] Campione M., La Fortezza M., Alvaro M., Scambelluri M., Malaspina N. (2020). ACS Earth Space Chemistry, 4 (6), 825830 